\title{
A pesca artesanal e os agravos à saúde do pescador no município de Curuçá, estado do Pará, Brasil
}

\author{
Laíse Carla Almeida da Conceição \\ Engenheira Agrônoma graduada pela Universidade Federal Rural da Amazônia (UFRA) \\ $\square$ laise.agronomia@gmail.com \\ Cyntia Meireles Martins \\ Engenheira Agrônoma; Doutora em Ciências Agrárias; Professora do Programa de Pós-Graduação em \\ Agronomia da Universidade Federal Rural da Amazônia (PGAGRO-UFRA) \\ $\bowtie$ cyntiamei@hotmail.com \\ Janayna Galvão de Araújo \\ Engenheira de Pesca; Doutora em Ecologia Aquática e Pesca pelo Programa de Pós-Graduação em Ecologia \\ Aquática e Pesca da Universidade Federal do Pará (PPGEAP-UFPA) \\ 凹anaynagalvao@yahoo.com.br \\ Fabrício Khoury Rebello \\ Economista; Doutor em Ciências Agrárias; Professor do Programa de Pós-Graduação em Agronomia da \\ Universidade Federal Rural da Amazônia (PGAGRO-UFRA) \\ $\square$ fabriciorebello@hotmail.com

\section{Marcos Antônio Souza dos Santos} \\ Engenheiro Agrônomo; Doutor em Ciência Animal; Professor do Programa de Pós-Graduação \\ em Agronomia da Universidade Federal Rural da Amazônia (PGAGRO-UFRA) \\ $\triangle$ fabriciorebello@hotmail.com
}

\section{Resumo:}

No Brasil, os pescadores artesanais chegam a quase um milhão de pessoas registradas e exercem suas atividades laborais expostos a graves riscos ocupacionais e sem proteção à saúde. Neste artigo, objetivou-se analisar as condições do trabalho e sua relação com a saúde dos pescadores artesanais no município de Curuçá, no estado do Pará. 0 método para de análise se baseou em questionários dirigidos com perguntas acerca dos dados socioeconômicos dos entrevistados, condição de vida e trabalho, e determinantes associados à vida pessoal, como idade e sexo, além de observações in loco. Como resultados, os pescadores são, na maior parte (68\%), de idade mais avançada, com mais de 41 anos, $93 \%$ deles não concluíram o ensino fundamental ou não possuem escolaridade. Principal causa disto é a iniciação na pesca artesanal desde muito cedo, 39\% alegaram pescar há mais de 31 anos. Concluiu-se que tantos anos de atividade e várias horas de trabalho diárias expõem os pescadores a diversos problemas de saúde (como dores nas costas, problemas de pele, lesões musculares, pressão alta e estresse) e, acidentes de trabalho (ferradas de animais e quedas). São necessárias ações governamentais na área de saúde que apoiem de forma profilática o trabalhador da pesca.

Palavras-chave: Desenvolvimento humano, Pesca artesanal, Saúde do trabalhador, Doenças ocupacionais. 


\title{
Artisanal fishing and fishermen's health problems in Curuçá municipality, Pará state, Brazil
}

\begin{abstract}
:
In Brazil, artisanal fishermen are almost one registered people and carry out their work activities exposed to serious occupational risks, and without health protection. This article aimed to analyze the work conditions, and their relationship with artisanal fishermen's health in Curuçá municipality, Pará state. The analysis method was based on questionnaires directed with questions about the interviewees' socioeconomic data, living and working conditions, and determinants associated with personal life, such as age and sex, in addition to on-the-spot observations. As a result, fishermen are, for the most part (68\%), of older age, over 41 years old. $93 \%$ of them have not completed elementary school or haven't any education level. The main cause of this is the initiation in artisanal fishing from an early age, $39 \%$ reported fishing for more than 31 years. We can conclude that so many years of activity and several hours of daily work expose fishermen to various health problems (such as back pain, skin problems, muscle injuries, high blood pressure, and stress) and, work accidents (animal stings and falls). Health governments are needed to prophylactically support fisheries workers.

Keywords: Human development, Artisanal fishing, Worker's health, Occupational diseases.
\end{abstract}

\section{La pesca artesanal y los problemas de salud de los Pescadores en el municipio de Curuçá, estado de Pará, Brasil}

\section{Resumen:}

En Brasil, los pescadores artesanales llegan a casi un millón de personas registradas y realizan sus actividades laborales expuestos a graves riesgos laborales y sin protección de la salud. En este artículo, el objetivo fue analizar las condiciones de trabajo y su relación con la salud de los pescadores artesanales del municipio de Curuçá, en el estado de Pará. El método de análisis se basó en cuestionarios dirigidos con preguntas sobre los datos socioeconómicos de los entrevistados, condición de la vida y el trabajo, y los determinantes asociados con la vida personal, como la edad y el sexo, además de las observaciones in situ. Como resultado, los pescadores son, en su mayoría (68\%), de edad avanzada, mayores de 41 años, el $93 \%$ de ellos no ha terminado la escuela primaria o no tiene escolaridad. La principal causa de esto es la iniciación en la pesca artesanal desde temprana edad, el $39 \%$ afirma pescar desde hace más de 31 años. Se concluyó que tantos años de actividad y varias horas de trabajo diario exponen a los pescadores a diversos problemas de salud (como dolor de espalda, problemas de piel, lesiones musculares, hipertensión arterial y estrés) y, accidentes laborales (picaduras de animales y caídas). Se necesitan acciones de salud gubernamentales para apoyar de manera profiláctica a los pescadores.

Palabras clave: Desarrollo humano, Pesca artesanal, Salud laboral, Enfermedades profesionales.

\section{INTRODUÇÃo}

A atividade da pesca é toda operação, ação ou ato tendente a extrair, colher, apanhar, apreender ou capturar recursos pesqueiros. No Brasil, a regulamentação da profissão de pescador ocorre pelo Decreto-Lei N 221/1967, que dispõe sobre a proteção e estímulos à pesca. Em 2009, foi aprovada a Lei N 11.959, que instituiu uma nova opção de contratação de pescadores, mediante acordos especiais, além da possibilidade desse processo ser amparado pela Consolidação das Leis do Trabalho (CLT). 
No Brasil, a pesca artesanal é desenvolvida em praticamente todo o território, possuindo numerosas e complexas especificidades, considerando, fatores socioeconômicos, políticos, institucionais e ambientais. Mais de 940 mil pescadores artesanais são registrados no Brasil, com responsabilidade pela segurança alimentar e abastecimento de pescado no país; em contrapartida, a pesca industrial oferece 40 mil empregos diretos (MARIN, 2017). Dos pescadores registrados no Brasil em 2010, 43,69\% (372.787) estão na região Nordeste e 38,76\% (330.749) estão na região Norte; as outras regiões, concentram apenas 17,54\% (BRASIL, 2012).

Considerando as regiões brasileiras, o Nordeste, onde vive a maior população pesqueira e também a mais pobre do Brasil, vem se constatando os maiores índices de produção nos últimos anos, sendo a pesca artesanal marinha a principal provedora. No Norte, a pesca artesanal é responsável pela maior parte do pescado capturado (MPA, 2013). Nas regiões Sudeste e Sul, por serem favorecidas por correntes marítimas frias, oferecem um maior potencial produtivo, capturado, principalmente, pela frota industrial (DA SILVA, 2015).

A pesca artesanal possui grande importância econômica na manutenção de arranjos produtivos, sendo uma das atividades humanas mais importantes e antigas na Amazônia, especialmente, para grande parte da população que reside nas margens dos rios, conferindolhes alimento e propiciando comércio, renda e lazer (SANTOS; SANTOS, 2005).

Para Freitas e Rodrigues (2015), os trabalhadores atuam sozinhos e/ou utilizam mão de obra familiar ou não assalariada, explorando ambientes ecológicos localizados próximos à região costeira, com embarcações de pouca autonomia. As técnicas de captura possuem características de baixo rendimento, e a produção é, em parte ou totalmente, repassada ao mercado, suprindo também o consumo familiar (CLAUZET; RAMIRES; BARRELLA, 2005).

Quanto a Classificação Nacional de Atividades Econômicas (CNAE), a atividade pesqueira é considerada de risco 3, potencialmente perigosa, porque expõe os trabalhadores a riscos de acidentes nos barcos, afogamentos, diversos problemas de saúde, trabalho noturno, contato com ambientes insalubres de trabalho e agentes patológicos em lugares com mal saneamento.

No ambiente ao qual o pescador artesanal se encontra, por vezes, ele precisa conviver com a degradação ambiental, principalmente, por conta da contaminação de esgotos, falta de saneamento, poluição química, industrial e agrotóxica. Há também, o efeito emergente das 
mudanças climáticas que ameaçam os recursos naturais, dos quais os pescadores são dependentes. Os territórios da pesca são ainda ameaçados pela sobrepesca, expansão do turismo associado à especulação imobiliária e grandes projetos portuários e industriais (PENA; GOMEZ, 2014).

Ademais, Figueiredo, Furtado e Castro (2009) ressaltam que a infraestrutura da maioria de municípios, vilas e povoados da Amazônia não ocorre pari passu ao seu crescimento demográfico local, ocasionando, uma série de carências que vão desde a falta de saneamento básico, dificuldade de acesso à água tratada e aos sistemas de saúde, além da insuficiente orientação técnica ao trabalhador da pesca, o que proporciona uma difícil vida cotidiana às suas populações.

Sendo assim, todas essas condições impõem restrições negativas à saúde do pescador, ressaltando um perfil epidemiológico composto de enfermidades pestilenciais transmissíveis, carências típicas da miséria e aos agravos à saúde decorrentes dos processos de trabalho (PENA; GOMEZ, 2014).

Quanto à caracterização típica da pesca artesanal familiar, a mesma ocorre em situações de vulnerabilidade econômica e social, principalmente, no emprego precoce dos membros mais novos, como crianças e adolescentes ou dos mais idosos. Freitas e Rodriguez (2015) afirmam que as consequências principais deste contexto socioeconômico e produtivo podem ser representadas pelo esmaecimento da atividade extrativa no arranjo local, como pelos efeitos sobre a saúde. Assim sendo, as doenças associadas estão na dependência do grau e magnitude da refuncionalização e da configuração territorial.

Diante desse quadro, o presente artigo contempla uma análise da condição da saúde ocupacional dos pescadores artesanais residentes no município de Curuçá, estado do Pará. Estudos dessa natureza são importantes para orientar políticas públicas no âmbito da saúde coletiva e de outras específicas quanto à atividade pesqueira. 


\section{A PESCA ARTESANAL NO ESTADO DO PARÁ E A SAÚDE DO TRABALHADOR DA PESCA}

No Pará, a produção de pescado é derivada de três segmentos de atividade: a pesca artesanal, industrial e a aquicultura. Cabe destacar que a pesca artesanal é realizada em praticamente todos os municípios do estado e corresponde a $84,23 \%$ da produção de pescado (IBAMA, 2007).

Esta é uma das atividades econômicas mais tradicionais do estado e que desempenha um importante papel socioeconômico na oferta de alimentos, ocupação de mão de obra e geração de renda. Além disso, também é dotada de significado simbólico, alicerçando a vida material e imaterial das populações envolvidas.

Quanto à forma de captura, a pesca paraense, normalmente, utiliza tecnologia simples, barcos de pequeno e médio portes, com apetrechos confeccionados pelos próprios pescadores ou adquiridos no mercado local (SANTOS; SANTOS, 2005). A pesca industrial e a aquicultura são desenvolvidas no estado, entretanto, com menor peso relativo na oferta de pescado (NOGUEIRA, SOUZA, SANTA BRÍGIDA, 2017).

A participação do estado no quadro de pescadores ativos e registrados foi a maior em 2010, de acordo com Brasil (2012), com 223.501 trabalhadores, também logrando o maior número de pescadoras no país, a saber 95.181 mulheres. No que tange à idade dos pescadores, o Pará se sobressai com a maior população de pescadores com idade menor que 40 anos, sendo a faixa etária de maior representatividade, a de pessoas com idade entre 30 e 39 anos, correspondendo a $28,44 \%$ do total.

Na região do Salgado Paraense, local onde se desenvolveu este estudo, a proximidade com o Oceano Atlântico evidencia, de acordo com Nogueira, Souza e Santa Brígida (2017), outras características nas atividades envolvidas de pesca, como as embarcações motorizadas e de médio porte, petrechos como redes de arrasto, espinhéis, currais e laço e redinha (para captura de caranguejos). o tempo para a execução da atividade costuma ser mais longo, com realização de viagens aos chamados "ranchos" (casebres construídos em locais estratégicos para a pesca, geralmente, longe das residências dos pescadores), que podem durar até mais de uma semana. 
Tais ranchos são utilizados para descanso, alimentação e higiene enquanto os pescadores estão empreendendo viagens para pescar. Porém, por vezes são instalações improvisadas, sem conforto e que abrigam muito mal os pescadores das intempéries, agravando a precariedade das condições envolvidas no trabalho, pela impossibilidade de repouso adequado.

Ademais, conforme Rosa e Mattos (2010), os pescadores artesanais estão sujeitos a vários fatores de risco oriundos das condições de vida e trabalho e pela falta de proteção, como radiação solar, variações climáticas, excesso de umidade, ruídos dos motores dos barcos, excesso de peso, agravados pela extensa jornada de trabalho e pouco uso de Equipamentos de Proteção Individual (EPI).

Prosenewicz e Lippi (2012) acrescentam à discussão que na atividade laboral da pesca sempre há risco de acidentes, afogamentos e outros perigos devido à inexistência ou precariedade quanto ao uso de Equipamentos de Proteção Individual (EPI), no entanto, está previsto no Sistema Único de Saúde (SUS), conforme artigo $6^{\circ}$, a execução de ações de saúde do trabalhador.

Conforme Boltanski (2004), os pescadores usam intensivamente seu corpo em seu trabalho, pois não podem parar de produzir, causando grandes desgastes, uma vez que "para os membros das classes populares [...] a doença se manifestará brutalmente, porque não se aperceberam dos sinais precursores ou porque se recusaram a percebê-los" (BOLTANSKI, 2004, pág. 148). Tal realidade é agravada devido à dificuldade costumeira em acesso médico da rede pública e a deficiência no saneamento básico (PROSENEWICZ; LIPPI, 2012).

Por seu turno, os riscos são classificados em cinco grandes grupos: físicos, químicos, biológicos, ergonômicos e os de acidentes que podem comprometer e agravar a saúde, como lesões na pele, problemas auditivos, oftalmológicos, urogenitais, entre outros (ROSA; MATTOS, 2010). E também risco de picadas de animais peçonhentos trazidos pelas águas (PROSENEWICZ; LIPPI, 2012).

A despeito dessa problemática é possível perceber prazer na atividade, fato afirmado por Brasil (2009): “...na fala dos pescadores [há] o prazer na realização do ofício. Vínculos afetivos são construídos gerando cooperação. ... Ressaltam que o trabalho em parceria 
demanda confiança, posto que até mesmo a vida do pescador depende da ajuda do parceiro de trabalho".

As dificuldades, riscos e desgastes físico e mental enfrentados pelos pescadores são recompensados pela alegria em desenvolver seu trabalho, especialmente de maneira coletiva, criando vínculos. Dejours et al. (1994) afirmam que a psique do trabalhador é importante para compreensão da saúde como um todo, pois as questões psíquicas são mobilizadoras de energia, podendo até interferir no estado físico, contribuindo também para desenvolvimento de doenças.

\section{METODOLOGIA}

O município de Curuçá se estende por $672,7 \mathrm{~km}^{2}$, tendo cerca de 34 mil habitantes que vivem basicamente da agricultura, da pesca e do extrativismo. O município conta com 16 postos de saúde municipais, 58 escolas de nível pré-escolar, 71 escolas de nível fundamental e três de ensino médio (IBGE, 2010).

Conforme Souza (2010), Curuçá assemelha-se a diversas localidades ribeirinhas da Amazônia, onde o cotidiano e as relações estabelecidas são marcados pela apropriação da natureza pelo homem. Assim, a relação da população curuçaense com o meio ambiente adquire diversos significados que englobam labor, sobrevivência e lazer, posto que Curuçá é um município predominantemente rural, ao qual metade da população está ligada à pesca (IBGE, 2010).

Vale destacar que Curuçá é o sexto município com maior representatividade na produção de pescado, sendo responsável por 2,35\% da produção estadual. No município existe a Colônia de Pescadores (Z-05), sendo uma das mais antigas do estado, tendo sido criada em 1920. Atualmente, a colônia conta com sete capatazias, que são representantes da colônia de pesca responsáveis pelo recolhimento da contribuição dos pescadores que envolve aproximadamente 2.340 filiados. 
Nesta pesquisa, diante da variedade dos riscos que a atividade de pesca possui, procurou-se identificar os mais comuns, provenientes do contato frequente com água e umidade, acidentes com animais que podem provocar lesões, radiação solar e enfrentamento de variações climáticas e problemas ergonômicos.

Para elaboração do questionário, valeu-se do modelo proposto por Dahlgren e Whitehead (1991) sobre os determinantes sociais da saúde, em que há níveis interdependentes de atuação direta e indireta sobre o processo saúde/doença de indivíduos. Primeiramente vêm as condições socioeconômicas, culturais e ambientais, em seguida, as condições de vida e de trabalho (acesso aos serviços públicos, educação, habitação e saúde). Subsequentemente, os determinantes associados às vidas pessoais, como fatores de idade e sexo.

Os questionários foram aplicados junto à 28 pescadores artesanais da Comunidade do Recreio, no mês de julho de 2018, usando o método snowball sampling, onde um respondente indica o outro. Vale ressaltar que a técnica proporcionou evidenciar nesta pesquisa, os pescadores de maior reconhecimento na Comunidade do Recreio, quer seja por longo tempo de pesca, conhecimento, tradição na família e prática no manejo de recursos naturais.

Após a coleta, as respostas quantitativas foram organizadas em um banco de dados e submetidas à análise estatística no programa Excel para elaboração de tabelas e gráficos. As demais informações foram analisadas qualitativamente, sendo obtidas por meio de entrevista informal junto ao Vice-Presidente da Colônia de Pescadores de Curuçá e observação in loco.

\section{RESULTADOS E DISCUSSÃO}

\section{Perfil socioeconômico}

Todos os entrevistados eram do sexo masculino, sendo $36 \%$ com mais de 50 anos, $32 \%$ dentro da faixa etária de 41 a 50 anos, 21\% com idade entre 31 e 40 anos e 11\% com menos de 30 anos. De modo similar, Freitas e Rodrigues (2015), identificaram a maior parte de seus entrevistados (40\%) representados na faixa etária de pescadores acima de 45 anos. Da mesma forma, Rosa e Mattos (2010), apontaram que 70,1\% de seus entrevistados eram de pescadores 
na faixa superior a 36 anos de idade. Tal fato demonstra que boa parte dos jovens não se sentem atraídos para exercer esse ofício.

Para Souza (2010), que realizou estudo na Reserva Extrativista Mãe Grande em Curuçá, existe um grande desinteresse das novas gerações quanto à atividade da pesca, sendo um dos fatores a pressão da atividade artesanal pela pesca industrial, o que faz aumentar o esforço do pescador na atividade bem como o aumento do tempo embarcado, trazendo o desestímulo dos jovens a continuar com o modo de vida dos pais.

Adiciona-se a isso que a escolaridade dos pescadores é baixa, 89,5\% responderam não possuir o ensino fundamental completo e 3,5\% não possui escolaridade. Quando cruzados os dados de idade e escolaridade, observa-se que apenas um pescador $(3,5 \%)$, com idade entre 31 e 40 anos respondeu ter completado o ensino fundamental e, um pescador $(3,5 \%)$ respondeu ter o ensino médio incompleto, com idade entre 20 e 30 anos. Tais resultados estão dentro do esperado, pois, do total de pescadores registrados no estado do Pará (67.252), 87,19\% são tidos como analfabetos ou com o ensino fundamental incompleto (SEAP/PR, 2006).

Assim, a maior idade do pescador aliado a falta de educação formal acaba por tornar a atividade da pesca como única opção laboral a esses trabalhadores. Como aponta Martins (2010), muitos jovens saem em busca de novas oportunidades de trabalho e estudo nas maiores cidades do estado do Pará como a capital Belém ou Castanhal, indo morar nas periferias.

Vale destacar que conhecer o nível de escolaridade dos pescadores é fundamental para se elaborar políticas públicas, a fim de "contribuir para um maior conhecimento acerca da realidade de vida e trabalho dos pescadores artesanais no Pará” (BRASIL, 2009).

Todos os entrevistados responderam possuir água encanada em suas residências, bem como fossa como destino de dejetos. Quanto ao descarte do lixo, 46,4\% pescadores informaram que queimam, $42,9 \%$ dispõe da coleta realizada pela prefeitura passando nas ruas de suas casas, sendo este, o descarte de seu lixo.

Quanto a frequência da visita do agente de saúde no domicílio dos pescadores, 39,3\% informaram que ocorre com certa frequência (ao menos uma vez ao mês), em contrapartida, $53,6 \%$ alegaram que as visitas são muito raras, chegando à nulidade. 


\section{Atividade da pesca artesanal}

A pesca é uma atividade tradicional e executada desde a infância pelos entrevistados, os dados indicaram que 39\% respondeu que pescam há mais de 31 anos e $18 \%$ que pescavam entre 21 e 30 anos. Note-se que a maior parte dos pescadores aprendeu a pescar com seus pais ou familiares, demonstrando tradição familiar no exercício laboral.

Em Curuçá é bastante comum a técnica da pesca com curral. Nesse sistema, empregase uma armadilha fixa, em forma de cerca feita de varas de madeira, armadas em beira de praias ou bancos de areia, com aproximadamente 20 a 30m de extensão. O curral possui abertura por onde os peixes penetram e com a baixa-mar, ficam aprisionados, quando se procede a despesca (MORAES, 2007).

Mais da metade dos pescadores (68\%) realizam a atividade exclusivamente em currais, sendo que $25 \%$ mesclam a pesca em curral com outras formas de pescar, como anzol, estacada e rede. Lourenço et al. (2003) identificaram que 88,4\% dos seus entrevistados desenvolviam a pesca artesanal no Nordeste Paraense, de modo contínuo, ao longo de todo o ano, sendo a prática mais comum à utilização de redes (malhadeiras e tarrafas), observada em $62 \%$ dos casos estudados.

Apenas 7\% disseram não possuir curral, e pescam com rede e/ou linha. O curral é uma técnica facilitadora na captura dos peixes, onde o trabalhador pode se apoiar no assoalho do curral para executar a despesca, o que gera menos desconforto ergonômico.

A percepção de $89 \%$ dos pescadores quanto à quantidade de peixes nos rios onde exercem sua atividade é que o recurso está diminuindo consideravelmente ao longo dos anos. Alguns atribuem ao intenso esforço de pesca oriundo da pesca industrial como causa principal desta diminuição, outros fatores expressos pelos entrevistados foram o aumento do número de pessoas que se tornaram pescadores no local em decorrência do desemprego e de falta de outras oportunidades de remuneração, além do uso de redes de arrastão.

Para o vice-presidente da colônia de pescadores de Curuçá, o problema também está relacionado aos barcos pesqueiros que vem dos estados do Maranhão e Ceará e que entre os meses de setembro a novembro podem ser encontrados na região em grande quantidade, chegando até 50 barcos industriais e que adentram a área dos pescadores artesanais. 
Assim, o esforço de pesca é aumentado, acarretando maiores problemas de saúde e maiores riscos à atividade. como por exemplo, tempo demasiado de exposição ao sol e problemas de coluna devido a postura irregular.

Conforme entrevista realizada com o vice-presidente da Colônia de Pescadores de Curuçá “antes tinha gente que educava sua família só com curral. Hoje você não vê mais isso”. Assim, muito pescadores, a despeito do curral, ainda precisam realizar a atividade de pesca embarcado, pois, "se não viajar no mínimo uns oito dias de barco, ele não consegue extrair o produto".

\section{Problemas de saúde ocupacional}

Diferentes trabalhos sobre saúde de pescadores artesanais apontam para problemas relacionados a doenças articulares, como dores na coluna, problemas respiratórios, de pele, envelhecimento precoce, entre outros, sendo enfermidades ligadas diretamente às atividades laborais, às circunstâncias ambientais e à situação de abandono e exclusão (GARRONE NETO, CORDEIRO, HADDAD JR., 2005; ROSA, MATTOS, 2008; BRASIL, 2009; ROSA, MATTOS, 2010; MELLO et al., 2012; PROSENEWICZ, LIPPI, 2012; PENA, GOMEZ, 2014; FREITAS, RODRIGUES, 2015; FREIRE, FERREIRA, 2015; MARIN, 2017; NOGUEIRA, SOUZA, SANTA BRÍGIDA, 2017). Na Tabela 1 (página seguinte) pode-se verificar as faixas de horas que os entrevistados responderam trabalhar, seu preparo físico para a atividade, ocorrência de acidentes ao longo dos anos como pescador e os principais problemas de saúde citados.

Quanto maior o número de horas trabalhadas, mais o pescador se expõe às intempéries e perigos concernentes à atividade. Aqueles que trabalham mais do que 5 horas por dia são os que possuem mais de um curral, ou além do curral, se valem de outras técnicas de pesca, exigindo mais tempo de deslocamento e captura.

Pena e Gomez (2014) argumentam que há necessidade de se manter longas jornadas de trabalho que podem chegar a 14 e 16 horas diárias, sem descanso semanal nem férias, pela necessidade de conseguir produtos o suficiente para venda com preços irrisórios impostos pela intermediação financeira, por ainda ser escassa a pratica da entrega do produto diretamente ao consumidor. 
Tabela 1 - Relação das horas de trabalho com preparo para a pesca (alongamento), ocorrência de acidentes e problemas de saúde apresentados pelos entrevistados.

\begin{tabular}{|c|c|c|c|c|c|c|c|}
\hline \multirow{3}{*}{$\begin{array}{c}\text { HORAS } \\
\text { MÉDIAS DE } \\
\text { TRABALHO }\end{array}$} & \multirow{3}{*}{$\%$} & \multicolumn{2}{|c|}{$\begin{array}{c}\text { FAZ } \\
\text { ALONGAMENTO }\end{array}$} & \multicolumn{2}{|c|}{$\begin{array}{l}\text { OCORRÊNCIA DE } \\
\text { ACIDENTE }\end{array}$} & \multirow{3}{*}{$\begin{array}{l}\text { PROBLEMAS DE } \\
\text { SAÚDE }\end{array}$} & \multirow{3}{*}{$\%$} \\
\hline & & NÃO & SIM & NÃO & SIM & & \\
\hline & & $\%$ & $\%$ & $\%$ & $\%$ & & \\
\hline \multirow{4}{*}{2 a 4} & \multirow{4}{*}{35,7} & \multirow{4}{*}{28,6} & \multirow{4}{*}{7,14} & \multirow{4}{*}{14,3} & \multirow{4}{*}{21,4} & Dores nas costas & 10,3 \\
\hline & & & & & & Lesão muscular & 10,3 \\
\hline & & & & & & Nenhum & 5,13 \\
\hline & & & & & & Problemas de pele & 5,13 \\
\hline \multirow{4}{*}{5 a 10} & \multirow{4}{*}{28,6} & \multirow{4}{*}{28,6} & & & \multirow{4}{*}{28,6} & Dores nas costas & 17,9 \\
\hline & & & & & & Estresse & 7,69 \\
\hline & & & & & & Doenças ósseas & 5,13 \\
\hline & & & & & & Nenhum & 2,55 \\
\hline \multirow{4}{*}{ Mais de 10} & \multirow{4}{*}{35,7} & \multirow{4}{*}{21,4} & \multirow{4}{*}{14,3} & \multirow{4}{*}{21,4} & \multirow{4}{*}{14,3} & Dores nas costas & 20,5 \\
\hline & & & & & & Vista & 7,69 \\
\hline & & & & & & Pressão alta & 5,13 \\
\hline & & & & & & Nenhum & 2,55 \\
\hline Total & 100 & 78,6 & 21,4 & 35,7 & 64,3 & & 100 \\
\hline
\end{tabular}

Ao se preparar para a pesca, 78,6\% dos pescadores não realizam qualquer tipo de alongamento. Quanto ao uso de Equipamento de Proteção Individual (EPI), o mais citado foi o chapéu (89,29\%), seguido de luvas $(75,00 \%)$ e botas (53,57\%), apenas um respondente $(3,57 \%)$ respondeu não utilizar qualquer tipo de proteção na pescaria. A ausência desses equipamentos pode potencializar riscos na condição de saúde, como problemas oftalmológicos (devido trabalhar no sol), pele, auditivos (alto barulho dos motores), entre outros. Mello et al. (2012) afirmam que a pouca utilização dos EPI's, vem intensificando o aparecimento de diversos acidentes de trabalho.

Dos entrevistados, $64,3 \%$ já sofreu algum tipo de acidente de trabalho, como queimaduras nos motores dos barcos, ferrada de animais e cortes diversos. Nogueira, Souza e Santa Brígida (2017) constataram que os acidentes mais comuns são as ferradas de arraia, bagres e picadas e ferrões de animais, e também quedas no interior da embarcação e para fora dela. Situação semelhante foi encontrada por Garrone Neto, Cordeiro e Haddad Jr. (2005) na região do médio Araguaia (Tocantins). Também havendo relatos de afogamentos que, nos casos mais críticos, levam o trabalhador à morte. 
Como consequência, a exposição ao trabalho sem EPI e por tempo prolongado de serviço estão na intensidade das ocorrências de problemas de saúde. Aqueles que trabalham por mais tempo (mais de 10 horas) são os que apresentaram maiores queixas (33,3\%). Dentro da faixa de 2 a 4 horas de trabalho por dia, 5,13\% chegaram a dizer que não sentem desconforto algum em sua saúde. A dor nas costas é a principal queixa dos trabalhadores, em qualquer faixa de carga horária de trabalho diário.

\section{CONCLUSÃO}

A atividade da pesca artesanal é realizada, majoritariamente, por homens de idade mais avançada e com baixa escolaridade. 0 maior esforço de pesca e exposição às intempéries ocasionadas por maior tempo de trabalho, tem ocasionado diversos problemas de saúde aos pescadores, fato atestado pelo grande número de acidentes de trabalho e ocorrência de doenças ligadas diretamente à atividade, conforme entrevistas.

Como decorrência, mesmo a atividade pesqueira sendo, em essência, transmitida de geração em geração, é comum que os jovens filhos de pescadores, tenham optado em migrar para outras localidades devido ao grande esforço e riscos inerentes à atividade.

É necessário políticas que possibilitem ampliação das estratégias da Saúde da Família não somente curativas como também preventivas, apoiando ao trabalhador da pesca no que tange o cotidiano de sua atividade laboral.

\section{REFERÊNCIAS}

BRASIL, S. S. Trabalho, adoecimento e saúde: aspectos sociais da pesca artesanal no Pará. 2009. Dissertação de Mestrado. Universidade Federal do Pará.

BRASIL. Ministério da Pesca e Aquicultura. Boletim estatístico da pesca eaquicultura: Brasil 2011. Brasília, DF, 2012 . Disponível em: <http://www.icmbio.gov.br/cepsul/images/stories/biblioteca/download/estatistica/est_2011_bol_bra.pdf>. Acesso em: 03.09.2017.

BOLTANSKI, L. As classes sociais e o corpo. São Paulo: Paz e Terra, 2004. 
CLAUZET, M.; RAMIRES, M.; BARRELLA, W. Pesca artesanal e conhecimento local de duaspopulações caiçaras (Enseada do Mar Viradoe Barra do Una) no litoral de São Paulo, Brasil. MultiCiência, Campinas, v. 4, p. 1-22, maio 2005. Disponível em: <www.multiciencia.rei.unicamp.br/artigos_04/rede_01_.pdf>. Acesso em: 01.09.2017.

DA SILVA, A. P. Pesca artesanal brasileira: aspectos conceituais, históricos, institucionais e prospectivos. Embrapa Pesca e Aquicultura-Boletim de Pesquisa e Desenvolvimento (INFOTECA-E), 2015.

DAHLGREN, G.; WHITEHEAD, M. Policies and strategies to promote social equity in health. Stockholm: Institute for Future Studies. Boston, 1991.

DEJOURS, C.; ABDOUCHELI, E.; JAYET, C.; BETIOL, M. I. S. Psicodinâmica do Trabalho: Contribuição da Escola Dejourianaà Análise da Relação Prazer, Sofrimento e Trabalho. São Paulo: Atlas, 1994.

FIGUEIREDO, E. M.; FURTADO, L. G.; CASTRO, E. R. Trabalhadores da pesca e a Reserva Extrativista Marinha Mãe Grande de Curuçá-PA: impactos socioambientais da Rodovia PA-136. Amazônia: Ci \& Desenv., Belém, v. 5, n. 9, jul./dez. 2009. Disponível em: <http://www.arquivo.cppnac.org.br/wpcontent/uploads/2012/04/CD_N_9_Trabalhadores_da_Pesca.pdf>. Acesso: 28 jul. 2018.

FREIRE, L. S.; FERREIRA, H. C. H. O turismo de base comunitária como alternativa de desenvolvimento local: o caso de Curuçá - Pará. ABET, Juiz de Fora, V.5, N. 3, P. 36 - 44, set./dez. 2015. Disponível em: <https://periodicos.ufjf.br/index.php/abet/article/view/3103>. Acesso: 28 jul. 2018.

FREITAS, M. B.; RODRIGUES, S. C. A. Determinantes sociais da saúde no processo de trabalho da pesca artesanal na Baía de Sepetiba, estado do Rio de Janeiro. Saúde e Sociedade, v. 24, p. 753-764, 2015. Disponível em: $<$ https://www.scielo.br/scielo.php?pid=S0104-12902015000300753\&script=sci_abstract\&tlng=pt>. Acesso: 28 jul. 2018.

GARRONE NETO, D.; CORDEIRO, R. C.; HADDAD Jr., V. Acidentes do trabalhoem pescadores artesanais da região do Médio Rio Araguaia, Tocantins, Brasil. Cadernos de Saúde Pública, Rio de Janeiro, v. 21, n. 3, p. 795-803, maio/jun. 2005. Disponível em: <http://www.scielosp.org/pdf/csp/v21n3/13.pdf>.Acesso em: 26.02.2018.

IBAMA. Estatística da pesca 2007 Brasil: grandes regiões e unidades da federação. Brasília, 2007.

INSTITUTO BRASILEIRO DE GEOGRAFIA E ESTATÍSTICA - IBGE. Dados socioeconômicos de Curuçá. Brasília, 2010. Disponível em: <http://www.ibge.gov.br/cidadesat/link.php?codmun=150290>. Acesso: 28 jul. 2018.

LOURENÇO, C. F.; FÉLIX, F. N.; HENKEL, J. S.; MANESCHY, M. C. A pesca artesanal no Estado do Pará. Belém: SETEPS/SINE-PA, 2003. 154p.

MARIN, R. E. A. Pescadores Artesanais em Tempos de Insegurança. In: NOGUEIRA, L. S. M.; SOUZA, D. M.; SANTA BRÍGIDA, A. M. B. Segurança e saúde dos pescadores artesanais no estado do Pará. São Paulo: Fundacentro, 2017, p. $87 . \quad$ Disponível em: <https://www.podprevenir.com.br/wpcontent/uploads/2017/02/Pesca_Artesanal_Portal.pdf>.Acesso em: 26.02.2018.

MARTINS, A. A. F. A. Caminho das águas: proposta para um aproveitamento de um subproduto ictiológico na Reserva Extrativista Mãe Grande de Curuçá. 2010. 181f. Dissertação (Mestrado). Núcleo de Meio Ambiente, Programa de Pós-Graduação em Gestão dos recursos. Área de Concentração: uso e aproveitamento dos recursos naturais. Belém, 2010.

MELLO, A. L. R.; BARRELLA, W; DOIMO, R. A. F.; RAMIRES, Milena. Perfil da saúde dos trabalhadores da pesca artesanal da estação ecológica de Juréia-Itatins-Peruíbe/SP. Unisanta Law and Social Science. p. 12 - 15; v. 1, n 1 (2012). Disponível em:<https://periodicos.unisanta.br/index.php/lss/article/view/77>. Acesso: 01 de set 2017.

MORAES, S. C. Uma Arqueologia dos Saberes da Pesca: Amazônia e Nordeste. Belém: EDUFPA, 2007.

MPA - Ministério da Pesca e Aquicultura. 2013. Boletim estatístico da pesca e aquicultura. Brasil 2011. Ministério da Pesca e Aquicultura. Disponível em: www.mpa.gov.br. Acesso: 01 de set 2017. 
NOGUEIRA, L. S. M.; SOUZA, D. M.; SANTA BRÍGIDA, A. M. B. Segurança e saúde dos pescadores artesanais no estado do Pará. São Paulo: Fundacentro, 2017, p. 87. Disponível em: <https://www.podprevenir.com.br/wpcontent/uploads/2017/02/Pesca_Artesanal_Portal.pdf>.Acesso em: 26.02.2018.

PENA, P. G. L.; GOMEZ, C. M. Saúde dos pescadores artesanais e desafios para a Vigilância em Saúde do Trabalhador. Ciência \& Saúde Coletiva, v. 19, n. 12, 2014 . Disponível em: $<$ https://www.scielo.br/scielo.php?pid=\$1413-81232014001204689\&script=sci_abstract\&tlng=pt $>$.Acesso em: 26.02.2018.

PROSENEWICZ, I.; LIPPI, U. G. Acesso aos Serviços de Saúde, Condições de Saúde e Exposição aos Fatores de Risco: percepção dos pescadores ribeirinhos do Rio Machado de Ji-Paraná, RO. Saúde Soc. São Paulo, v.21, n.1, p.219231, 2012. Disponível em: <https://www.scielo.br/scielo.php?script=sci_abstract\&pid=S0104$12902012000100021 \& \operatorname{lng}=$ en\&nrm=iso\&tlng=pt >.Acesso em: 26.02.2018.

ROSA, M. F. M.; MATTOS, U. A. O. A saúde e os riscos dos pescadores e catadores de caranguejo da Baía de Guanabara. Ciência \& Saúde Coletiva. 2010; 15 (supl.1): 1543-52. Disponível em: $<$ https://www.scielo.br/scielo.php?pid=S1413-81232010000700066\&script=sci_abstract\&tlng=pt $>$.Acesso em: 26.02.2018.

SANTOS, G. M.; SANTOS, A. C. M. Sustentabilidade da pesca na Amazônia. Estudos Avançados, 19 (54), 2005. Disponível em: <https://www.scielo.br/scielo.php?script=sci_arttext\&pid=S0103-40142005000200010>.Acesso em: 26.02.2018.

SEAP - Secretaria Especial de Aquicultura e Pesca da Presidência da República. Registro Geral da Pesca. Resultados do Recadastramento nacional dos pescadores do Brasil. Brasília: SEAP/ PR, 2006.

SOUZA, C. B. G. A gestão dos recursos naturais da Amazônia: A reserva extrativista Mãe Grande de Curuçá-PA. Revista Geografar, Curitiba, v. 5, n.1, p. 83-104, 2010. Disponível em: <https://periodicos.ufpa.br/index.php/revistamargens/article/view/2761>.Acesso em: 26.02.2018.

\section{(cc) EY}

Este trabalho está licenciado com uma Licença Creative Commons - Atribuição 4.0 Internacional. 